\title{
Seasonal Contrast in Precipitation Mechanisms over Nepal Deduced from Relationship with the Large-Scale Climate Patterns
}

\author{
Madan Sigdel $^{\mathbf{1}}$ and Motoyoshi Ikeda ${ }^{\mathbf{2}}$ \\ ${ }^{1}$ Central Department of Hydrology and Meteorology \\ Tribhuvan University \\ Kirtipur, Kathmandu \\ ${ }^{2}$ Graduate School of Environmental science \\ Hokkaido University \\ Sapporo, Japan \\ e-mail: sigdelbro@gmail.com
}

\begin{abstract}
Summer precipitation dominates over winter one for the annual total in south Asia, while the winter condition is still important for agricultural productions. Rain gauge data over Nepal were analyzed with large-scale atmospheric patterns such as El Niño-Southern Oscillation (ENSO) and Indian Ocean Dipole (IOD). In the period of June to September, summer monsoon rainfall over Nepal (SMRN) is generally higher in the eastern region along with a peak in the central region associated with the local orography. Its interannual variability was found to be correlated with the southern oscillation index (SOI): i.e., when La Niña occurs, eastward moisture flux is blocked over Bay of Bengal (BOB) by the anomalous Walker circulation extending from the Pacific. The local-scale condition for higher SMRN is implied by a main moisture route along the eastern arm of the low pressure in northeastern India, as proved by a significant correlation between SMRN and the northward moisture flux. In winter (DJFM), precipitation occurs more in the western region. The higher winter precipitation over Nepal (WPN) was correlated almost equally with positive Dipole Mode Index (DMI) over the Indian Ocean and also SOI, while the relationship with SOI is reversed from summer. A clear linkage was suggested with moisture flux from the Arabian Sea and the further western region. Thus, possible impacts of anomalous precipitation have to be predicted under the relationship with the large-scale indices depending on seasons.
\end{abstract}

Key words: precipitation, Nepal, ENSO, IOD

\section{Introduction}

\section{Background and climatology}

Hydroclimatology provides information on how the climate system causes time and space variations in the hydrologic cycle. The relationship between the climate system and the hydrologic cycle underlies floods, drought and possible future influences of global warming on water resources (Shelton 2009). According to the IPCC fourth report (Parry et al. 2007), impacts on the water sector due to global warming will decrease water availability and increase drought in mid-latitudes and semi-arid low-latitudes. The report suggested an increase in mean annual precipitation in south Asia, while the seasonal distributions are not clear yet.
The summer monsoon dominates south Asia from June through September and transports high moisture from the Indian Ocean to Nepal. The winter monsoon appears as strong northeasterly winds under influences of the Siberian High and is marked by occasional, short rainfalls in the lowlands and plains and snowfalls in the high-altitude areas (Kalsi 1980). The snow cover over Tibetan Plateau also creates a horizontal temperature gradient in the mid troposphere. This, together with topography of the Plateau, forces the migration of the cold air from the Siberian High to take southward routes. The amount of precipitation resulting from the northeasterly trade winds, which are modified by the winter monsoon, varies considerably but increases markedly with elevation. The winter precipitation in the form of snowfalls over 
Himalayas is important for generating sufficient melt water in spring and summer, which is critical for irrigation in the lower hills and valleys where agriculture predominates.
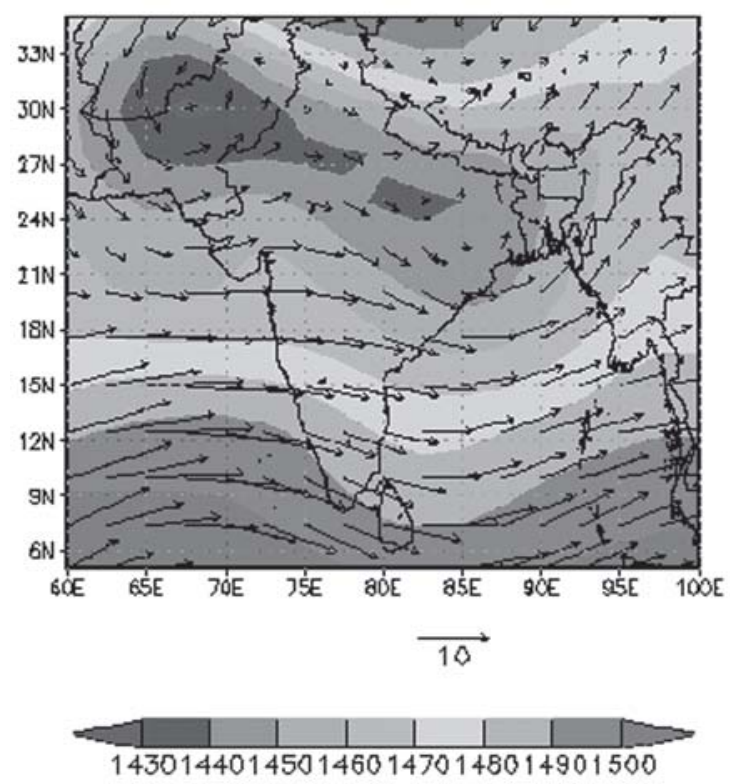

(a)
Fig. 1 shows the summer and winter climatology of geopotential height and horizontal wind at the lower atmosphere. We can clearly see the difference in the wind directions between summer and winter. Similarly,
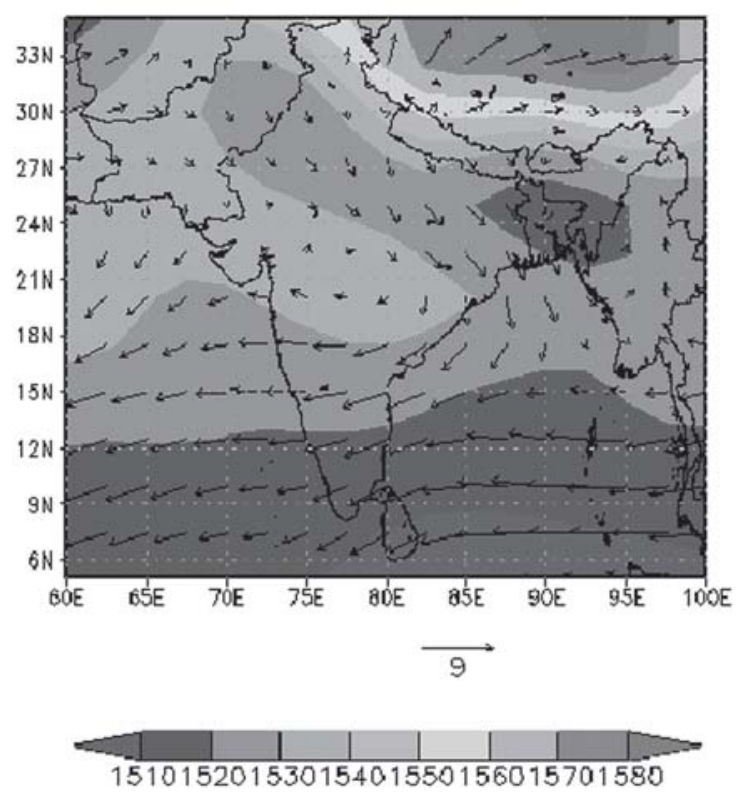

(b)

Fig.1. (a) Summer and (b) winter climatology of the geopotential heights (shading, unit: gpm) and superimposed horizontal winds (vector, unit: $\mathrm{m} / \mathrm{s}$ ) at $850 \mathrm{hPa}$.

the geopotential height in summer is low around Indian plains and Nepal, but the geopotential height in winter shows much weaker features. The climatology

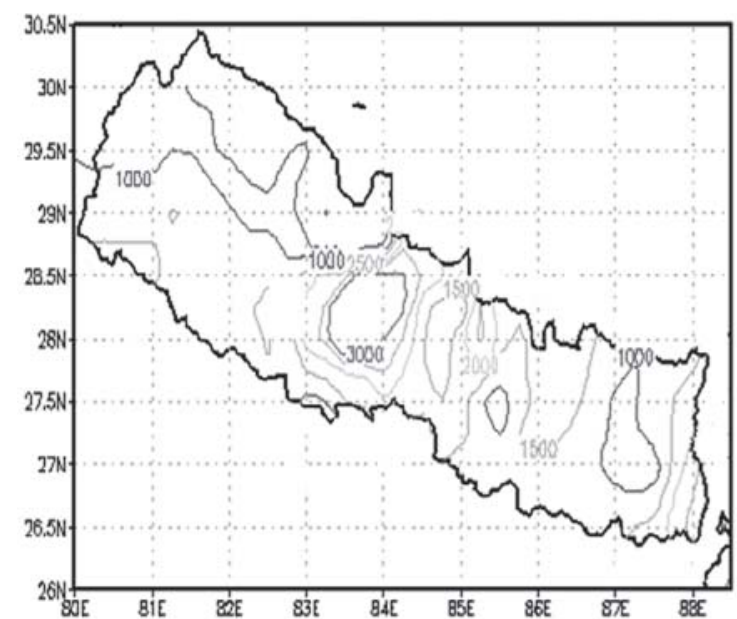

(a) of summer and winter precipitation patterns in Fig. 2 is characterized by summer high in central and also eastern Nepal and winter high in western Nepal.

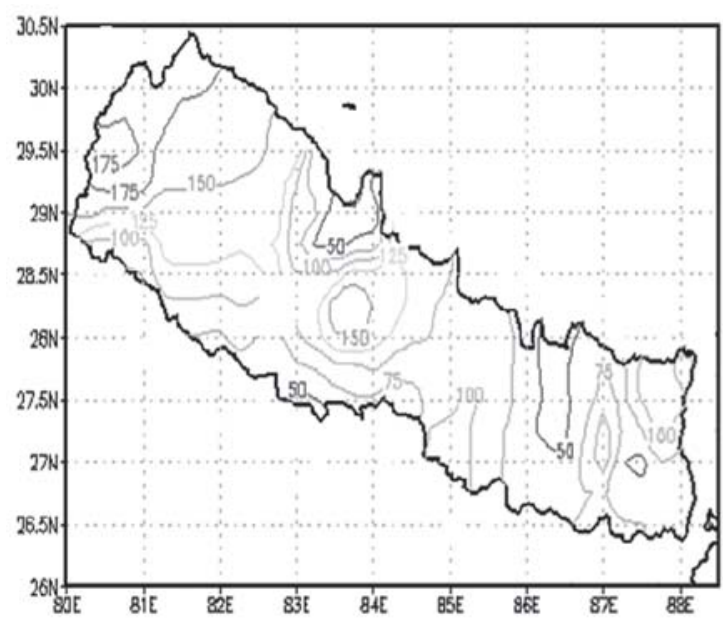

(b)

Fig. 2. Seasonal precipitation climatology of Nepal in (a) summer-JJAS and (b) winter-DJFM ( unit: mm) 


\section{Sigdel \& M. Ikeda/Seasonal Contrast in.......}

Nepal is one of the steepest territories in the world. Its topography varies from plain low land in south to higher Himalaya range towards north, contributing the complicated precipitation patterns. Climatic regimes vary from subtropical in the southern plains to frozen land in the northern mountain range. Altogether 26

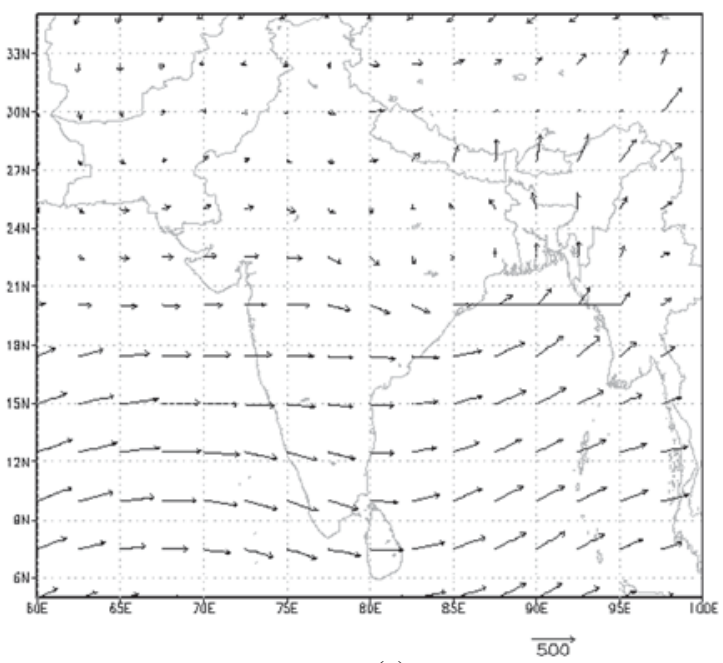

(a) unevenly distributed precipitation stations were used for this study representing different geographical areas like Mountains, Hills and Plain land.

Moisture fluxes are very much associated with the wind patterns at the lower atmosphere, as shown in Fig. 3. It is well expected that SMRN is supported by

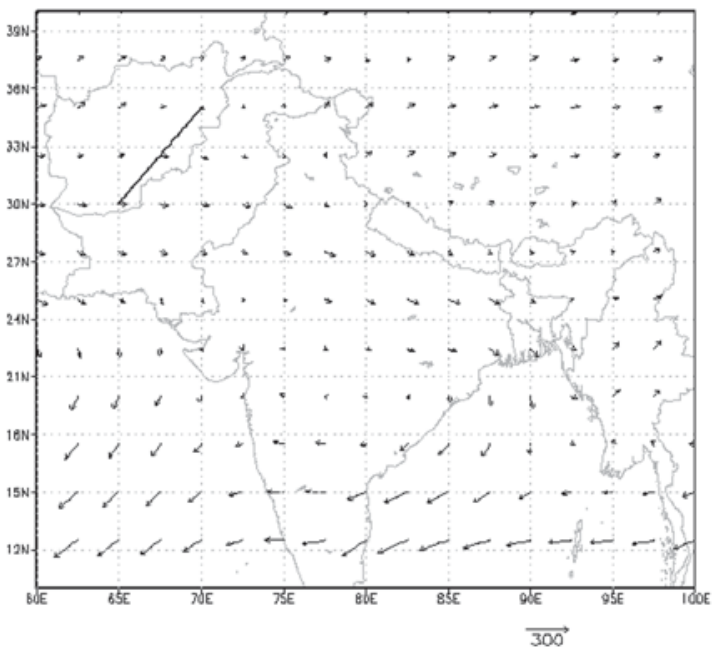

(b)

Fig. 3. Moisture flux vectors vertically integrated up to $500 \mathrm{hPa}$ averaged over (a) summer and (b) winter with a unit of $\mathrm{kg}$ $\mathrm{m}^{-1} \mathrm{~s}^{-1}$, along with the horizontal sections through which moisture transports are calculated.

the northward moisture flux from $\mathrm{BOB}$, while the eastward component in lower latitudes ( 5 to $15^{\circ} \mathrm{N}$ ) releases a potential accumulation towards the Pacific Ocean. The patterns around Nepal indicate western influences on WPN in latitudes of 25 to $35^{\circ} \mathrm{N}$. The additional contribution may come from the Arabian Sea under interannual variability.

\section{Previous studies on interannual variability}

As for interannual variability, the most frequently cited index is SOI, which represents ENSO. The positive (negative) SOI indicates La Niña (El Niño), corresponding to cold (warm) Niño 3 region $\left(5^{\circ} \mathrm{N}-\right.$ $5^{\circ} \mathrm{S}, 170^{\circ} \mathrm{W}-120^{\circ} \mathrm{W}$ ) in the eastern Pacific. The influence of ENSO on south Asian precipitation occurs through the variability in the Walker and Hadley circulation cells (Goswami 1998, Krishnamurthy \& Goswami 2000, Singh 2001). Shrestha et al. (2000) found SMRN fluctuation without a distinct long-term trend. Shrestha (2000) reported SMRN during 1957-88 in relation with SOI: i.e., higher (lower) SMRN is associated with positive (negative) SOI. ENSO has a dominant cycle of 3-4 years (De \& Mukhopadhyay
1999), although, over the last couple of decades, El Niño occurs more frequently and takes longer persistence (Houghton et al. 2001).

Ashok et al. (2001) proposed that the event of no summer drought over India, despite of the strongest El Niño in the century, was explained by the positive dipole phase in the Indian Ocean. This newly found climate index, DMI, is defined as the normalized difference in sea surface temperature (SST) anomalies between the western and the eastern Equatorial Indian Ocean, and has a high negative correlation with precipitation in the equatorial Indian Ocean but a low correlation over central and northern India. We have yet to know of any impact on the climate in Nepal.

Rao (1999) examined the winter precipitation in India with SOI and found significant negative correlations in some part of Indian continent. Yadav et al. (2007) found the significant relations between northwestern India winter precipitation and SOI, suggesting a key role of sea surface temperature in the equatorial Indian Ocean. Kripalani and Kumar (2004) suggested the relationship of DMI with northeast monsoon rainfall 
over southeastern India: i.e., the positive (negative) DMI enhanced (suppressed) the rainfall. Sakai and Kawamura (2009) reported that convective heating shifted northward from the equator under El Niño and tended to increase precipitation in south Asia. They proposed also an eastward propagation of stationary waves from Europe to the Arabian Sea, which appeared to reinforce the subtropical teleconnection over south Asia.

In section 2, the rain gauge data and the atmospheric data are introduced, and the statistical methods are explained, along with the calculation of moisture flux. Main results are shown and discussed in section 3 on the relationship between rainfall and large-scale atmospheric patterns. Section 4 presents the summary and is extended to possible consequences of the expected future climate change.

\section{Methodology}

The monthly mean precipitation data were provided at 26 stations by the Nepal Government's Department of Hydrology and Meteorology and used in this study for the period of January 1971 to December 2003. Thus, SMRN data have a time span for 33 years, while WPN data start in 1972. Both SMRN and WPN were produced through an ordinary average of all station data. Since the stations were distributed unevenly, a simple test, in which the mean values were produced without one station in the precipitation peak around $84^{\circ} \mathrm{E}$ and the other station around $85.5^{\circ} \mathrm{E}$, was carried out. The correlations were very high (0.9) in the seasonal data between the two averaging methods, guaranteeing reliability of the ordinary average.

The station precipitation data in winter are relatively better represented by CPC Merged Analysis of Precipitation (CMAP) data and the GPCP precipitation. In contrary, the summer precipitation is systematically less in CMAP and GPCP, nearly half of the station data. The interannual variations also show low correlation with the summer station data. Hence, we expect more reliable analyses of precipitation mechanisms using the station data. In addition, we checked the APHRODITE data (Yatagai et al. 2009) and compared with raingauge station data of mean annual precipitation over Nepal. We found that APHRODITE provides a similar pattern with raingauge but gives lower precipitation amount, in particular over central Nepal.
Climatology and daily reanalysis data of winds, specific humidity, geopotential height and outgoing longwave radiation (OLR) at $2.5^{\circ} \times 2.5^{\circ}$ resolution were provided for the same period (1971-2003) by the National Centre for Environmental Prediction/ National Centre for Atmospheric Research (NCEP/NCAR). Monthly SOI was taken from Climate Prediction Center, National Oceanic and Atmospheric Administration (NOAA), while DMI was taken from JAMSTEC (http:// www.jamstec.go.jp). Correlation analyses were performed using the standard statistical method, and additional analyses were carried out on the regression of the reanalysis fields on SMRN, WPN and the other climate indices.

A moisture flux analysis was made up using the daily reanalysis data around Nepal and the concerned region. The fluxes were calculated across the zonal section for SMRN in the southeastern region at $20^{\circ} \mathrm{N}$ (85-95 $\left.{ }^{\circ} \mathrm{E}\right)$ over Bangladesh and compared with that at $20^{\circ} \mathrm{N}\left(70-80^{\circ} \mathrm{E}\right)$ in the southwestern region, where the vertical integration was taken up to $850 \mathrm{hPa}$. As for WPN, the southeastward flux in DJFM was taken across the western section $\left(30^{\circ} \mathrm{N}, 65^{\circ} \mathrm{E}-35^{\circ} \mathrm{N}, 70^{\circ} \mathrm{E}\right)$, and the northward flux as well across the zonal section at $20^{\circ} \mathrm{N}\left(70-80^{\circ} \mathrm{E}\right)$.

\section{Results and Discussion}

\section{Correlation with climate indices}

The relationship between SMRN and the large-scale atmospheric indices was examined first for the common season (JJAS). During the period of 33 years, 20 occasions possessed an in-phase relationship between SMRN and SOI with the same sign, as shown in Fig.4a. The correlation coefficient (CC) between them is 0.52 , which is above the $99 \%$ confidence level (Table 1 ). In the low phase of SOI (SOI<-0.5), the average deficit of SMRN is $8.1 \%$, while the average excess is $7.5 \%$ in the high phase (SOI>0.5). Here, the low phase refers to El Niño years 1972, 76, 77, 82, 87, 91, 93, 94, 97 and 2002, when the standardized values of both SOI and SMRN are negative. The high phase refers to La Niña years 1974, 75, 81, 88, 96 and 98 . These results are basically consistent with Shrestha (2000). The additional correlation was examined between SMRN and SOI (Table 2). Table 2 shows also the correlations of SOI with rainfall in concurrent monsoon (JJAS) and succeeding post-monsoon (ON). The higher correlation appears between SOI in the mature phase $(\mathrm{ON})$ and the simultaneous precipitation. 
Table 1. Correlations between precipitation and climate indices during the common seasons: i.e., June to September for SMRN, and December to March for WPN

\begin{tabular}{l|l|l}
\hline & SOI & DMI \\
\hline SMRN & 0.52 & -0.28 \\
WPN & -0.39 & 0.42 \\
\hline
\end{tabular}

Table 2. Correlations between SMRN and SOI in two periods, along with the correlations between the simultaneous precipitation and SOI

\begin{tabular}{l|l|l}
\hline SOI & JJAS & ON \\
\hline SMRN & 0.52 & 0.26 \\
Simultaneous precipitation & 0.52 & 0.57 \\
\hline
\end{tabular}

An indicator of the east-west temperature gradient across the tropical Indian Ocean, linked to the IOD, is referred to as DMI and used in the correlation analysis. The correlation results between SMRN and DMI are shown in Table 1 and Fig.4a. Here, we used only the

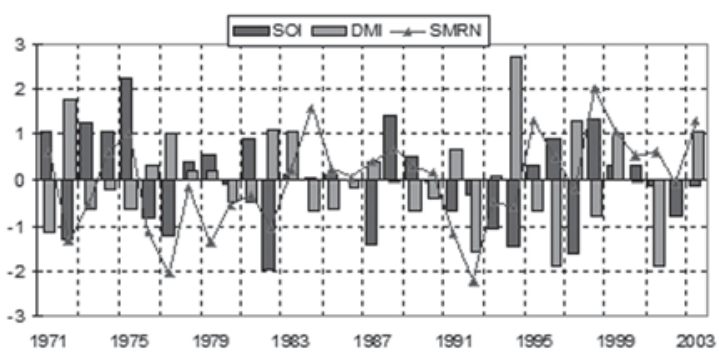

(a) simultaneous correlation (i.e., for JJAS). The CC is 0.28 between SMRN and DMI and statistically marginal, while it is -0.59 between SOI and DMI. Thus, SOI and DMI are not independent of each other statistically, and they should be considered with much care.

First we assumed the following possibility: SOI is an independent variable, and both DMI and SMRN are related with SOI, which results in a correlation between SMRN and DMI. We took out the correlated parts in DMI and SMRN with SOI, and performed a correlation analysis on the residuals that are uncorrelated with SOI. The result from this analysis showed an extremely low correlation (0.03) between the residuals of SMRN and DMI. Similarly for the other case, DMI was considered as an independent variable, while SMRN and SOI were treated as dependent variables. The consequent correlation is higher CC (0.46) between the residuals SMRN and SOI. From these analyses, we can finally conclude that SMRN is related with SOI, but not with DMI.

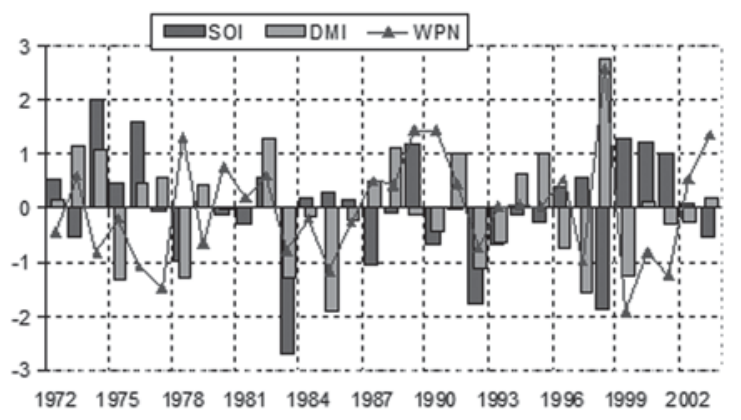

(b)

Fig. 4. Standardized anomalies of (a) SMRN and (b) WPN with SOI and DMI averaged over JJAS (June-September) and DJFM (December-March), respectively.

We tried to link WPN with various climate indices like SOI, DMI and North Atlantic Oscillation (NAO) from the Pacific Ocean, the Indian Ocean and the Atlantic Ocean, respectively. At the first step we calculated the correlation coefficients among them (Table 1). WPN has correlations of -0.39 with SOI and 0.42 with DMI. Both DMI and SOI are significantly correlated with WPN at 95\% confidence level at degrees of freedom of 31, while WPN is not significantly correlated with $\mathrm{NAO}$ at $\mathrm{CC}=0.18$ (not shown in Table 1 ). Note that the sign for SOI is opposite from that with SMRN. The correlation with DMI is qualitatively similar to northeast monsoon rainfall over southeastern India
(Kripalani \& Kumar 2004), whereas it is noted that the timing of the monsoon is October-to-December and different from WPN.

In the same way as SMRN, the residuals were examined among WPN, SOI and DMI. Once SOI is an independent variable, we took out the correlated parts in DMI and WPN with SOI. The correlation coefficient is 0.45 between the residuals of DMI and WPN. When DMI was considered as an independent variable, WPN and SOI were treated as dependent variables with the consequent correlation of -0.43 . It is noted that the original SOI and DMI have null correlation, and hence, the residuals have a little higher correlation among 
them than the original set has. Thus, WPN variability can be similarly attributed to SOI and DMI. Once SOI and DMI are not correlated with each other, it is worthwhile to check the multiple correlation of WPN with SOI and DMI. The CC is 0.48 , significant at $99 \%$ confidence level.

The WPN results are discussed with reference to Sakai and Kawamura (2009). They did not mention the relationship with DMI, but pointed out the effects of NAO. Their concern was more towards mid- to high latitudes in Asia, where the linkage seems robust with the Atlantic. On the other hand, the shift in the tropical convection system, which was claimed to be important for precipitation variability over south Asia, could be associated with DMI without conflict against the present results.

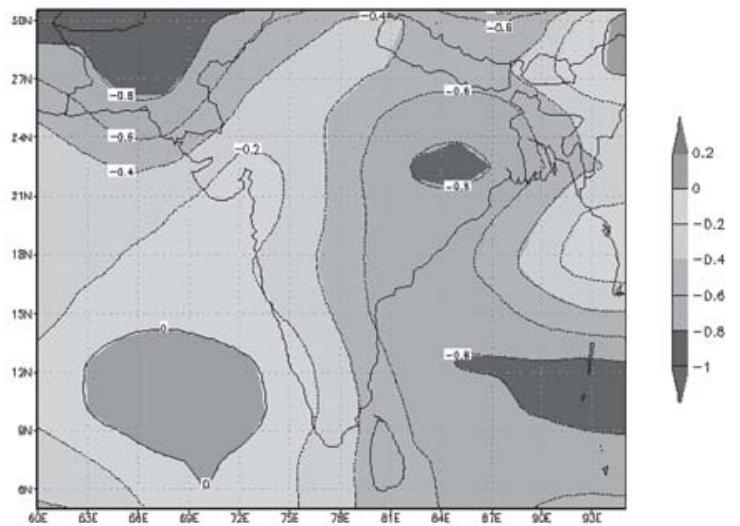

(a)

\section{Geopotential height and winds}

Geopotential height and wind vectors were regressed on SMRN, SOI and DMI at different vertical levels. Their association with SMRN and the large-scale indices can hint the control mechanisms over SMRN. The geopotential height and winds at $850 \mathrm{hPa}$ are shown in Fig.5a and 6a. The regressed wind is clearly northwestward from Bangladesh up to Nepal, with easterly flow in 5 to $15^{\circ} \mathrm{N}$ turning northward in the northern BOB. By comparing this pattern with the climatology in Fig.1a, an appropriate interpretation would be that the eastward moisture leakage is reduced in 5 to $15^{\circ} \mathrm{N}$ and instead supplied to Bangladesh and Nepal. Thus, the winds play an important role in the moisture flux up to Nepal.

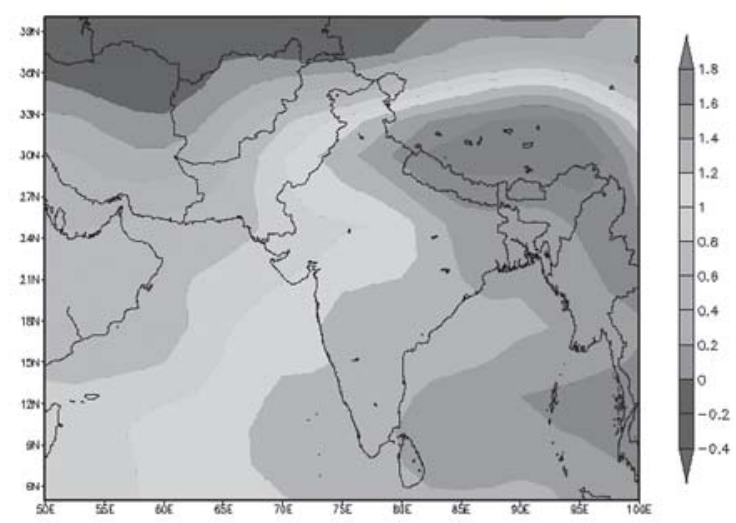

(b)

Fig. 5. Seasonal geopotential heights at $850 \mathrm{hPa}$ regressed on (a) SMRN and (b) WPN.

The common feature in the regression maps between SMRN and SOI is wind from the head of BOB in the northwestward direction (figure not shown for SOI). This wind pattern is consistent with and well expected from the positive correlation between SMRN and SOI. In the case of the regression on DMI, the wind is fundamentally opposite to those on SMRN and SOI, because of the inverse relation of DMI with SMRN. Near Nepal, however, the wind is very weak and not effective for a role of DMI on SMRN.

The geopotential field at $850 \mathrm{hPa}$ regressed on WPN is shown in Fig.5b, along with the winds in Fig.6b. We can notice the low pressure in western Asia near Iran and Afghanistan along with the wide northeast-tonorthward flow to western Nepal from the Arabian Sea and the equatorial Indian Ocean. The climatology maintains a route from Afghanistan, carrying more moisture associated with the westerly jet which takes a southward undulation in northern India (Fig.1b). The other route supplies moisture from the equatorial region by a gentle but wide flow via central India (Fig.5b \& 6b). The climatology shows northerly winds over India (Fig.1b), implying that the Hadley circulation weakens and permits a northward moisture flux.

\section{OLR}

Fig.7a shows the summer monsoon OLR regressed on SMRN, describing a clear negative anomaly in northern India and Nepal. The climatic OLR has a low center over southern India and spreads northward. Low values of OLR indicate higher cloud tops and consequent positive anomalies of precipitation. The core of negative OLR anomaly has the east-west length 


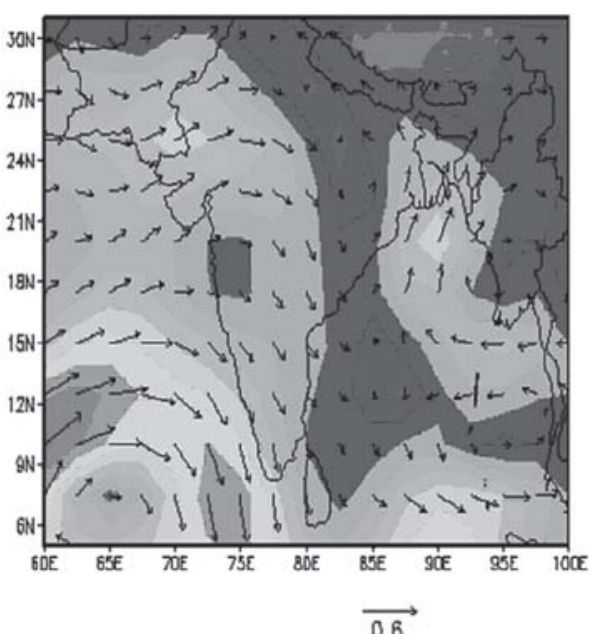

(a)
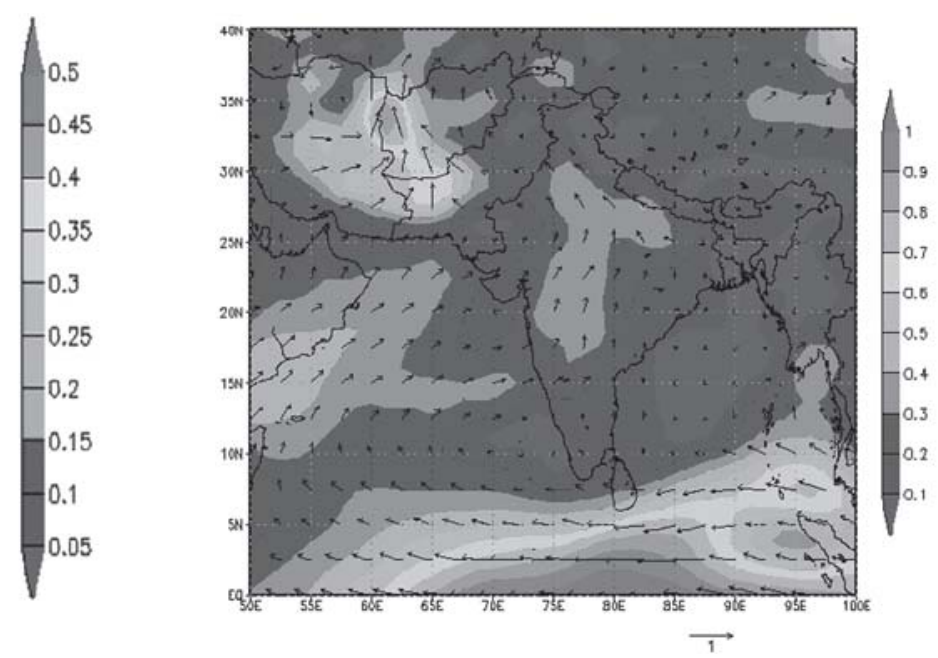

(b)

Fig. 6. Wind at 850 hPa regressed on (a) SMRN and (b) WPN. The significant levels are 0.35 in summer and 0.33 in winter at $95 \%$ confidence level.

of $1000 \mathrm{~km}$ and the north-south width of $500 \mathrm{~km}$ having a correlation of -0.21 with SMRN. This marginal correlation suggests smaller-scale processes more responsible for heavy SMRN. The geopotential height regressed on SMRN has the extension of a low pressure anomaly in northeastern India (Fig.5a) and situated under the eastern part of the low OLR. Then, we extended the analyses to the moisture fluxes, which are expected to support low OLR and a favorable condition for moisture available for SMRN.

OLR regressed on WPN is shown in Fig.7b. The lower anomaly spreads from Pakistan/ Afghanistan boarder to Nepal. However the OLR anomaly in winter is weaker

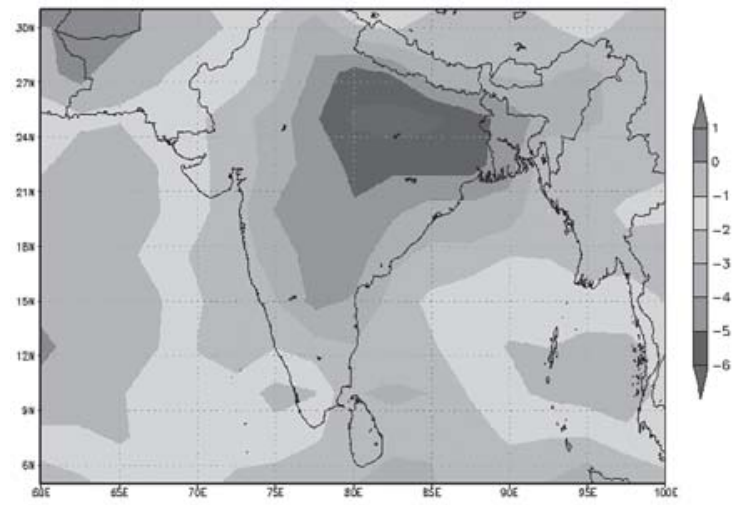

(a) than in summer, indicating a gentle and broad convergence of moisture.

\section{Moisture transport}

The regression analyses on SMRN suggested the contribution of the monsoonal flow passing to Nepal through the BOB side rather than the Arabian Sea side. Therefore, SMRN was correlated with the northward moisture flux across the zonal section $20^{\circ} \mathrm{N}\left(85-95^{\circ} \mathrm{E}\right)$ over BOB (Fig.3a). The mean moisture transport crossing the zonal section of $20^{\circ} \mathrm{N}$ is $8.02 \times 10^{14} \mathrm{~kg} /$ season for the summer monsoon season. As moisture moves from ocean to land, it is gradually precipitated with a traveling distance from the source. SMRN and

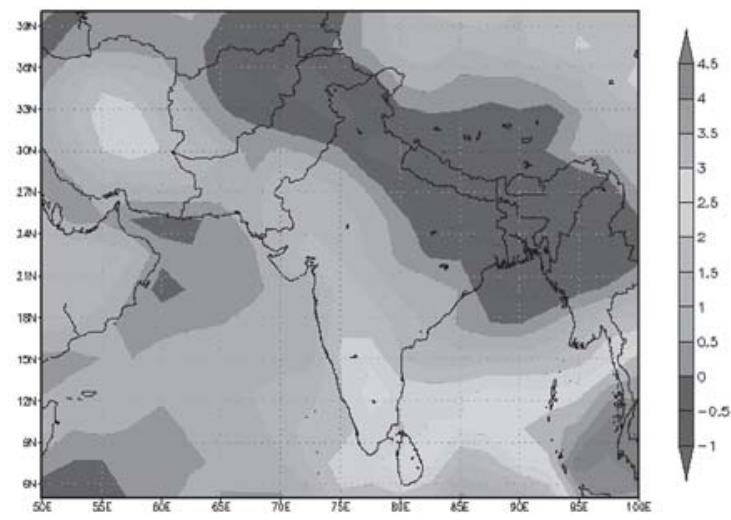

(b)

Fig. 7. Outgoing longwave radiation (OLR) anomalies (unit: $\mathrm{Wm}^{-2}$ ) regressed on (a) SMRN and (b) WPN 
the flux are plotted in Fig. 8a. The CC between SMRN and the moisture transport is 0.36 at $20^{\circ} \mathrm{N}$ (Table 3) above the 95-percent confidence level.

Table 3. Correlation between respective precipitation and moisture fluxes across the sections in Fig. 3 and also the zonal section in the southwestern region $20^{\circ} \mathrm{N}\left(70-80^{\circ} \mathrm{E}\right)$.

\begin{tabular}{l|l|l}
\hline & $\begin{array}{l}\text { BOB section/ } \\
\text { Afghanistan section }\end{array}$ & $\begin{array}{l}\text { Sections in } \\
\text { western India }\end{array}$ \\
\hline SMRN & 0.36 & 0.08 \\
WPN & 0.35 & 0.33 \\
\hline
\end{tabular}

The correlation is very low (0.08) between SMRN and the flux across the southwestern section $20^{\circ} \mathrm{N}(70$ $\left.80^{\circ} \mathrm{E}\right)$. Thus, it is clearly shown that the additional moisture takes the route over BOB and contributes higher SMRN. Combination of the regression analyses and the moisture flux analyses told us that the Walker circulation above the Pacific Ocean expands towards the Indian Ocean and accumulates extra moisture over BOB. The Hadley circulation then carries the moisture to Bangladesh and Nepal.

For WPN, the western source was suggested to be more important. Therefore, the flux was calculated across the section $\left(30^{\circ} \mathrm{N}, 65^{\circ} \mathrm{E}-35^{\circ} \mathrm{N}, 70^{\circ} \mathrm{E}\right)$ in Fig. $3 \mathrm{~b}$ and shown in Fig.8b. The CC is 0.35 above the 95\% confidence level. The flux was also calculated across the southwestern section $20^{\circ} \mathrm{N}\left(70-80^{\circ} \mathrm{E}\right)$ to be 0.33 . Therefore both routes, through Afghanistan from west and through western India from the equatorial region, seem equally important.

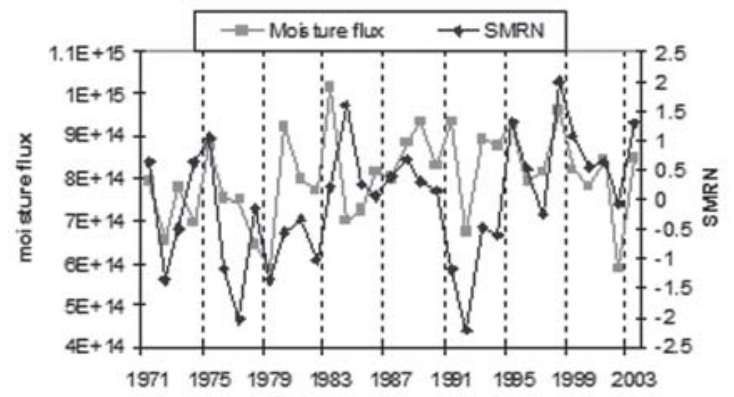

(a)

\section{Summary statistics}

We analyzed the summer and winter circulation systems and their influences on Nepal precipitation as they are separated into summertime-SMRN and wintertime-WPN for this study. The interannual variability of SMRN was found to be correlated with the SOI, while the role of DMI on SMRN appears only through their correlations with SOI: i.e., more (less) rainfall occurs during La Niña (El Niño). The controlling factor of SMRN is the moisture flux carried along the eastern arm of relatively low pressure in eastern India, as proved by a significant correlation between SMRN and the moisture flux through the zonal section over the BOB. The statistical relationship between tropical Pacific circulations (e.g. ENSO) and summer monsoon around northern India is consistent with the established finding: e.g., Goswami (1998) and Krishnamurthy and Goswami (2000).

Based on the statistical analyses, the significant aspect of anomalous SMRN is the moisture flux from BOB, showing higher precipitation as the high cloud core over northern India. SMRN has higher CC (0.52) with SOI than CC (0.36) with the moisture flux from BOB. The difference might be related with a role of local reevaporation and other local phenomena. The further analysis and modeling would be useful to determine the role of synoptic depressions, which could enhance uphill winds and convection around Nepal.

WPN dominant in western Nepal showed the correlations similarly with SOI and DMI, while the role of SOI is opposite to the summer one. A clear linkage was suggested with moisture flux from the Arabian Sea and the equatorial Indian Ocean and also the flux from the further western region near Afghanistan. The

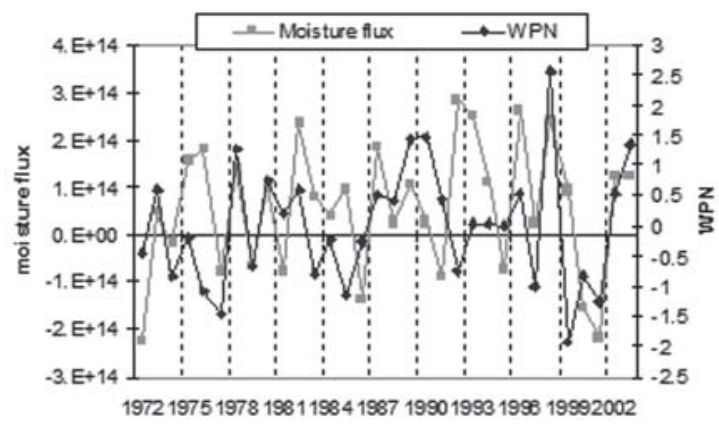

(B)

Fig. 8. Interannual variations (kg/season) of (a) the northward moisture transport in JJAS across the zonal section at $20^{\circ} \mathrm{N}$ $\left(85-95^{\circ} \mathrm{E}\right)$ and (b) the southeastward transport in DJFM across the western section $\left(30^{\circ} \mathrm{N}, 65^{\circ} \mathrm{E}-35^{\circ} \mathrm{N}, 70^{\circ} \mathrm{E}\right)$ along with the standardized SMRN and WPN anomalies, respectively. 


\section{Sigdel \& M. Ikeda/Seasonal Contrast in........}

moisture route from Arabian Sea and equatorial Indian ocean can be explained by either El Niño or positive Indian Dipole. This result partially agrees with Rao (1999), who suggested the relationship with SOI. The latter route is not directly related to El Niño and Dipole, but indicates a mid-latitude phenomenon similarly to the idea suggested by Sakai and Kawamura (2009).

In the present study, the differences between summer and winter were focused on. Since precipitation in a whole year is crucial to agriculture, glacier and land slide, a full-scale study would be desirable by examining the onset date of heavy rain in summer, ratios of the days over certain thresholds of daily precipitation in each season, and snowfall amount. This type of study will be carried out in future for possible impacts associated with climate change.

\section{Acknowledgements}

Nepal Government's Department of Hydrology and Meteorology is acknowledged for providing station data. The first author was supported by MEXT scholarship through Japanese Government.

\section{References}

Ashok, K., Z. Guan and T. Yamagata. 2001. Impact of the Indian Ocean Dipole on the relationship between the Indian monsoon rainfall and ENSO. Geophyical Research Letters 28: 4499-4502.

De, U.S. and P.K. Mukhopadhyay. 1999. The effect of ENSO/Anti ENSO on northeast monsoon rainfall. Mausam 504: 343-354.

Goswami, B.N. 1998. Interannual variations of Indian summer monsoon in a GCM: External conditions versus internal feedbacks. Journal of Climate 11: 501-522.

Houghton, J.T., Y. Ding, D.J. Griggs, M. Noguer, P.J. van der Linden and D. Xiaosu, Eds. 2001. Climate change 2001: The scientific basis: Contributions of Working Group I to the Third Assessment Report of the Intergovernmental Panel on Climate Change, Cambridge University Press, Cambridge, United Kingdom and New York, NY, USA, 881 p.
Kalsi, S.R. 1980. On some aspects of interaction between middle latitude westerlies and monsoon circulation. Mausam 38: 305-308.

Kripalani, R.H., and P. Kumar. 2004. Northeast monsoon rainfall variability over south peninsular India vis-àvis the Indian ocean dipole mode. International Journal of Climatology 24: 1267-1282, doi:10.1002/joc.1071.

Krishnamurthy, V. and B.N. Goswami. 2000. Indian monsoon-ENSO relationship on inter decadal time scales. Journal of Climate 13: 579-595.

Parry, M.L., O.F. Canziani, J.P. Palutikof, P.J. van der Linden and C.E. Hanson, Eds. 2007. Climate Change 2007: Contribution of Working Group II to the Fourth Assessment Report of the Intergovernmental Panel on Climate Change, Cambridge University Press, Cambridge, United Kingdom and New York, NY, USA.

Rao, G.N. 1999. Variation of SO relationship with summer and winter monsoon rainfall over India: 1872-1993. Journal of Climate 12: 3486-3495.

Sakai, K. and R. Kawamura. 2009. Remote response of the East Asian winter monsoon to tropical forcing related to El Niño-Southern oscillation. Journal of Geophysical Research 114. D06105, doi:10.1029/2008JD010824.

Shelton, M.L. 2009. Hydroclimatology perspective and applications, Cambridge University Press, 436 p.

Singh, O.P. 2001. Multivariate ENSO index and Indian monsoon rainfall: relationship on monthly subdivisional scale. Meteorology and Atmospheric Physics 78: 1-9.

Shrestha, A.B., C.P. Wake, J.E. Dibb and P.A. Mayyewski. 2000. Precipitation fluctuation in the Nepal Himalaya and its vicinity and relationship with some large scale climatology parameters. Inernational Joural of Climatology 20:317-327.

Shrestha, M.L. 2000. Interannual variation of summer monsoon rainfall over Nepal and its relation to Southern Oscillation Index. Meteorology and Atmospheric Physics 75: 21-28.

Yadav, R.K., K. Rupa Kumar and M. Rajeevan. 2007. Role of Indian Ocean Sea surface temperature in modulating northwest Indian winter precipitation variability. Theoritical and Applied Climatology 87: 73-83.

Yatagai et al. 2009. A 44-year daily grided precipitation dataset for Asia based on a dense network of rain gauges. SOLA 5: 137-140. 
Nepal Journal of Science and Technology Vol. 13, No. 1 (2012) 